\title{
Control and comparison of the antioxidant capacity of beers
}

\author{
Paula Alexandra Ribeiro Tafulo ${ }^{\mathrm{a}, \mathrm{b}}$, Raquel Barbosa Queirós ${ }^{\mathrm{a}, \mathrm{b}}$, Cristina Maria Delerue-Matos ${ }^{\mathrm{b}}$, \\ Maria Goreti Ferreira Sales ${ }^{\mathrm{b}, *}$
}

a Instituto de Engenharia e Sistemas de Computadores do Porto, Unidade de Optoelectrónica e Sistemas Electrónicos, Departamento de Física da Faculdade de Ciências da Universidade do Porto, Porto, Portugal

${ }^{\mathrm{b}}$ REQUIMTE/Instituto Superior de Engenharia do Porto, Porto, Portugal

\section{A R T I C L E I N F O}

\section{Article history:}

Received 21 January 2010

Accepted 15 May 2010

\section{Keywords:}

Antioxidant capacity

Trolox

Ascorbic acid

Gallic acid

TRAP

TEAC

DPPH

FRAP

ORAC

CUPRAC

Beers

\begin{abstract}
A B S T R A C T
The purpose of the present work is to determine the antioxidant capacity (AC) of 27 commercial beers. The AC indicates the degree of protection of a certain organism against oxidative damage provoked by reactive oxygen and nitrogen species.

Assays were carried out by the following methods: (i) total radical trapping antioxidant parameter (TRAP); (ii) trolox equivalent antioxidant capacity (TEAC); (iii) trolox equivalent antioxidant capacity (DPPH); (iv) ferric-ion reducing antioxidant parameter (FRAP); (v) cupric reducing antioxidant capacity (CUPRAC); (vi) oxygen radical absorbance capacity (ORAC). Ascorbic acid (AA), gallic acid (GA) and trolox (TR) were used as standards.

All beers showed antioxidant power, but a wide range of ACs was observed. The effect of several factors upon these differences was studied. Statistical differences were found between ACs of beers of different colours. ORAC method provided always higher experimental ACs, of significant statistical differences to other assays.
\end{abstract}

(c) 2010 Elsevier Ltd. All rights reserved.

\section{Introduction}

Beers raw materials are water, malt, non-malted cereals, hops and yeast. Beers can be classified as ale or lager considering the kind of fermentation they are subjected to. Ale beers are produced after a "high" fermentation process, meaning that the yeast stays on top, with fermentation temperature ranging from 15 to $25^{\circ} \mathrm{C}$. These kinds of beers have a pronounced taste of hops and have alcohol contents between $4 \%$ and $8 \%$. Lager beers have a deep or "low" fermentation, the yeast stays in the bottom, and the fermentation is carried out at $5-10^{\circ} \mathrm{C}$.

Beer is a worldwide traditional natural beverage, with low calories and no fat, with organic acids and vitamins (coming from malt), proteins, hop (a mild sedative and an appetite stimulant) and water. Beer has a higher nutritional value than other alcoholic beverages, because of its minerals and essential nutrients such as potassium, magnesium, calcium and sodium. The use of cereals and malt to produce beer may also contribute for the ingestion of naturally occurring antioxidant $(\mathrm{AO})$ compounds, such as poly-

\footnotetext{
* Corresponding author. Address: REQUIMTE/Instituto Superior de Engenharia do Porto, R. Dr. António Bernardino de Almeida, 431, 4200-072 Porto, Portugal. Tel.: +351228 340 500; fax: +351228321 159 .

E-mail addresses: mgf@isep.ipp.pt, goreti.sales@gmail.com (M.G.F. Sales).
}

phenols. Therefore, a possible benefit from beer consumption, not yet studied, may derive from its AO proprieties (Ghiselli et al., 2000b; Girotti, Bolelli, Fini, Budini, \& Arfelli, 2002; Wei, Mura, \& Shibamoto, 2001). AOs are "any substance that, when present at low concentrations compared with those of an oxidizable substrate, significantly delays or prevents oxidation of that substrate" (Halliwell, 2007). AOs act in various ways, which include complexation of redox-catalytic metal ions, scavenging of free radicals, and decomposition of peroxides.

The intensity of this effect depends on the chemical structure and concentration of the AO present.

The antioxidant capacity (AC) is the measurement of moles of a given free radical scavenged by a test solution, independently of the antioxidant present in the mixture (Mello \& Kubota, 2007). There are various assays described in literature for AC determination. Oxygen radical absorbance capacity (ORAC) and total radical trapping antioxidant parameter (TRAP) are based on hydrogen atoms transfer (HAT) that monitor competitive kinetic reactions $\left(M(n)+e(\right.$ from $\left.A O) \rightarrow A O^{\bullet}+M(n-1)\right)$ (Huang, Ou, \& Prior, 2005). Trolox equivalent antioxidant capacity (TEAC), ferric-ion reducing antioxidant parameter (FRAP), trolox equivalent antioxidant capacity (DPPH), and cupric reducing antioxidant capacity (CUPRAC) assays are based on the electron transfer (ET) of a reduction reaction $\left(R O O^{\bullet}+A O \rightarrow R O O H+A^{\bullet}\right.$ ) (Huang et al., 2005). 
TRAP method was developed by Wayner, Burton, Ingold, and Locke (1985). It is based on the generation of peroxyl radical by the attack of an azo compound to a substrate. Typically, these radicals have enough energy to extract hydrogen from a substrate. When 2,2-azinobis(3-ethylbenzothiazoline-6-sulfonate acid) (ABTS) is added to the azo compound 2,2'-azobis(2-amidinopropane) dihydrochloride (AAPH), the formation of ABTS radical cation occurs. The formed radical gives to the solution a blue colour that in the presence of AOs acting as reducing agents becomes colourless by the reduction of the ABTS radical. This reaction can be monitored by spectrophotometry at $734 \mathrm{~nm}$ (Campos, Escobar, \& Lissi, 1996; Ghiselli, Serafini, Natella, \& Scaccini, 2000a; Vasconcelos et al., 2007; Wayner et al., 1985).

TEAC assay was first reported by Miller, Rice-Evans, Davies, Gopinathan, and Milner (1993), in 1993 and improved in 1999 by Re et al. (1999). This method is based in a decolourization technique similar to that of TRAP method. The blue/green ABTS radical cation is produced by reacting ABTS with potassium persulphate (Obón, Castellar, Cascales, \& Fernández-López, 2005). By adding antioxidants to this solution, the ABTS radical cation goes back to its stable and colourless original form, ABTS. The decolourization indicates the decay of the radical species by its reduction after the addition of an AO. The corresponding decrease in absorbance is monitors by spectrophotometry at $734 \mathrm{~nm}$ (Huang et al., 2005; Re et al., 1999). This method is normally applied to food samples due to its simplicity. TEAC monitors the decay of ABTS radical caused by the addition of AO.

FRAP assay measures the sample capacity to reduce a substrate. This method is based on ET, using $\mathrm{Fe}(\mathrm{III})(\mathrm{TPTZ})_{2} \mathrm{Cl}_{3}$ as oxidant. FRAP assesses the reduction of the $\mathrm{Fe}$ (III) complex to $\mathrm{Fe}$ (II), that occurs due to the presence of reducing agents (AOs). The $\mathrm{Fe}(\mathrm{II})(\mathrm{TPTZ})_{2}$ complex has a purple colouration and its absorbance is read at $593 \mathrm{~nm}$ over time, because the absorbance increases slowly up to several hours. There are not many differences between this assay and TEAC once the redox potential of $\mathrm{Fe}(\mathrm{III})$ is comparable to the radical ABTS, with the exception that FRAP is carried out at acidic $\mathrm{pH}$ and TEAC is carried out on a neutral $\mathrm{pH}$ (Benzie \& Strain, 1996, 1999; Huang et al., 2005; Pulido, Bravo, \& Saura-Calixto, 2000). This method was developed by Benzie \& Strain (1996), and in 1999 Benzie and Strain (Benzie \& Strain, 1999) renamed it.

DPPH is one of the few stable nitrogen organic radicals. The nitrogen electron in DPPH molecule gives it a purple colouration that becomes colourless in the presence of AOs. This is a simple method but some disadvantages limit its application. Many antioxidants that react rapidly with peroxide radicals may have a very slow reaction to DPPH or may even be inert to it (Huang et al., 2005; Kurechi, Kikugawa, \& Kato, 1980). The reaction progress is monitored by a spectrophotometer at $525 \mathrm{~nm}$.

CUPRAC is based on the reduction of $\mathrm{Cu}$ (II) to $\mathrm{Cu}(\mathrm{I})$ by an $\mathrm{AO}$. The $\mathrm{Cu}(\mathrm{II})$-neocuproine complex, $\mathrm{Cu}(\mathrm{II})-\mathrm{Nc}$, is reduced in the presence of $\mathrm{AO}$ and the formed complex has a maximum absorbance at $450 \mathrm{~nm}$. This method has several advantages regarding other methods based in ET, such as its simplicity, reagent stability and reproducibility (Apak et al., 2007).

ORAC determines the absorption capacity of oxygen radicals and measures the decreasing of fluorescence emission. In this method, the APPH radical reacts rapidly with oxygen, originating a more stable peroxyl radical (ROO.). This radical oxidizes fluorescein, decaying the measured signal. When an AO is present, ROO. attracts a hydrogen of the AO instead of fluorescein to form a hydroperoxyl (ROOH). ORAC combines time and inhibition percentage of the radical by the $A O$ and uses of area under the curve (AUC) to quantify the protective effect of the AO (Huang, Ou, Hampsch-Woodill, Flanagan, \& Prior, 2002; Ou, Huang, Hampsch-Woodill, Flanagan, \& Deemer, 2002).
Thus, all the AC assays rely on a different chemical backgrounds. Therefore, the analysis of the same sample by each of methods may provide quite different results (Prior, Wu, \& Schaich, 2005; PérezJiménez et al., 2008; Serrano, Goñi, \& Saura-Calixto, 2007): each $\mathrm{AO}$ in a complex sample has a different activity pattern in each method, thus providing different results amongst the different assays. The interfering effect from co-existing compounds in each method is also variable from sample to sample. Therefore, to ensure that a sample is indeed the one of higher AC, several methods and standards should be used and their results compared.

The present work describes the analysis of commercial beers from different commercial brands, kind of fermentation (ale or lager), origin, colourants, flavours, antioxidants (AOs), sweeteners, alcohol, colour, juice, and other additives by means of TRAP, TEAC, FRAP, DPPH, CUPRAC, and ORAC methods, and with AA, GA and TR standards. The effect of the previous factors upon the observed $A C$ differences was evaluated by means of ANOVA tests.

\section{Experimental}

\subsection{Reagents}

All reagents were pro analysis (p.a.) quality. Different standards were used for record calibration curves: AA (Riedel-de-Haën, Germany), GA (Fluka, Switzerland) and TR (Fluka, Switzerland). Sodium acetate tri-hydrated and acetic acid (Merck, Switzerland), AAPH (Sigma-Aldrich, Switzerland), ABTS (Fluka, Switzerland), Sodium persulphate (Fluka, Switzerland), Phosphoric acid 85\% (Riedel-de-Häen, Germany), Dipotassium hydrogen phosphate (Riedel-de-Häen, Germany), DPPH (Sigma-Aldrich, Switzerland), TPTZ (Fluka, Switzerland), iron chloride (III) hexa-hydrated (Merck, Germany), Chloridic acid (Carlo Erba, Italy), Ammonium acetate (Merck), Neocuproine (Sigma-Aldrich, Switzerland), Acetic acid (Merck, Germany), Copper chloride (II) (M\&B, England), Potassium Phosphate (Riedel-de-Häen, Germany), Phosphoric acid (Riedel-deHäen, Germany), and Fluorescein (Riedel-de-Häen, Germany) were also used. Deionized water of $0.054 \mu \mathrm{Sm}^{-1}$ was used throughout.

\subsection{Samples}

In this study 27 samples of beer were used, all purchased from local supermarkets. Eighteen beers were Portuguese and the others were Belgian. The Portuguese beers were Super Bock (Single, Tango, Green, Lemon, Stout, Without Alcohol, Peach, Abadia and Black), Sagres (Single, Bohemia D'ouro, Bohemia, Zero Black and Black), Imperial, Auchan, Jumbo and Tagus. The Belgian beers were Grimbergen (Cuvée de L' Ermitage, Optimo Bruno, Tripel, Blondeand Double), Leffe (Blonde, Radiense, Brune and Vieille Luvée).

\subsection{Equipment}

Absorbance values were measured by a Thermo Scientific Evolution $300 \mathrm{UV}-\mathrm{Vis}$ spectrophotometer ( \pm 0001 units of absorbance) using plastic or quartz cells of $1 \mathrm{~cm}$ optical path and $3.5 \mathrm{~mL}$ capacity. The $\mathrm{pH}$ was monitored by a combined glass electrode connected to a Crison ${ }^{\circledR}$ GLP pH meter. A thermostatized Shakerbath SBS 30 was used to keep samples at $37^{\circ} \mathrm{C}$ in FRAP method. Solids were weighted in a Sartorius BP $211 \mathrm{D}\left( \pm 10^{-6} \mathrm{~g}\right)$. Volumes were rigorously measured by Gilson ${ }^{\circledast}$ automatic micropipettes of adjustable volume.

\subsection{Assays}

All beers were analyzed on the author's laboratory. On TRAP assay, a solution of AAPH $(2 \mathrm{mM})$ and ABTS $(75 \mu \mathrm{M})$ prepared in 
sodium acetate buffer ( $50 \mathrm{mM}, \mathrm{pH}$ of 4.3$)$ was incubated at $45^{\circ} \mathrm{C}$ for $60 \mathrm{~min}$. The solution was brought to room temperature. A volume of $2400 \mu \mathrm{L}$ of the above described solution was mixed with $800 \mu \mathrm{L}$ of sample in a cell. The absorbance was read at $734 \mathrm{~nm}$, 15 min after the reaction started. The standard concentrations ranged 1.3-35 $\mu \mathrm{M}$ for both AA and TR, and 1.3-10 $\mu \mathrm{M}$ for GA. Linear regression of each curve was used to determine the AC of samples, expressed in $\mu \mathrm{M}$ of each standard (Campos et al., 1996).

For TEAC assay a solution of $7 \mathrm{mM}$ of ABTS and $2.45 \mathrm{mM}$ of sodium persulphate was prepared in a phosphate buffer ( $\mathrm{pH}$ of 7 ) and incubated over night in the dark to give a very intense greenish blue solution. $12.5 \mathrm{~mL}$ of this solution were diluted in $500.0 \mathrm{~mL}$ of phosphate buffer ( $\mathrm{pH}$ of 7). Two-thousand microliters of this solution were placed in a cell and mixed with $900 \mu \mathrm{L}$ of water and $100 \mu \mathrm{L}$ of the sample. The absorbance was read at $734 \mathrm{~nm}$, 15 min after the reaction started. For both standards AA and TR the range of concentration used was $1.7-46.7 \mu \mathrm{M}$ and $0.7-13.3$ for GA (Huang et al., 2005).

On FRAP assay, $200.0 \mathrm{~mL}$ of acetate buffer (23 mM pH of 3.6) were mixed with $20.0 \mathrm{~mL}$ of TPTZ $(20.0 \mathrm{mM}), 20.0 \mathrm{~mL}$ of $\mathrm{FeCl}_{3} \cdot 6 \mathrm{H}_{2} \mathrm{O} 20 \mathrm{mM}$, and $12 \mathrm{~mL}$ of deionised water. TPTZ solution was dissolved in $\mathrm{HCl}(40 \mathrm{mM})$ at $50^{\circ} \mathrm{C}$. One thousand five hundred microliters of the previously described reagent was mixed with $1300 \mu \mathrm{L}$ of acetate buffer, $30 \mu \mathrm{L}$ of sample, and $170 \mu \mathrm{L}$ of deionised water in a cuvette cell. This mixture was kept at $37^{\circ} \mathrm{C}$. Absorbance readings were made at $593 \mathrm{~nm}$ every $30 \mathrm{~min}$ till absorbance stabilization. The range of concentration used for AA and TR standards was $0.8-33.2 \mu \mathrm{M}$ and $0.8-16.6 \mu \mathrm{M}$ to GA standard.

For DPPH method, a solution of DPPH $(0.19 \mathrm{mM})$ was prepared in $2: 1(\mathrm{v} / \mathrm{v})$ of ethanol and sodium acetate $(0.1 \mathrm{M}) ; 2800 \mu \mathrm{L}$ of this solution and $200 \mu \mathrm{L}$ of sample were mixed in a cell. The decolouration of the DPPH radical was measured at $525 \mathrm{~nm}, 10 \mathrm{~min}$ after the reaction started. The concentration range for AA and TR was 1.7-50 $\mu \mathrm{M}$ and 3.3-66.7 $\mu \mathrm{M}$ to GA.

CUPRAC assay required three different solutions: copper (II) chloride $\left(1.0 \times 10^{-2} \mathrm{M}\right)$, ammonium buffer $(1 \mathrm{M}$, pH of 7) and neocuproine $\left(7.5 \times 10^{-3} \mathrm{M}\right)$ in $96 \%$ ethanol. One microliter of $\mathrm{Cu}(\mathrm{II})$, $1 \mathrm{~mL}$ of buffer and $0.1 \mathrm{~mL}$ of sample were mixed in a cell, and the absorbance was read at $450 \mathrm{~nm}, 30 \mathrm{~min}$ after the reaction started. The range of concentration for GA was $0.6-18.3 \mu \mathrm{M}$ and $1.2-61.0 \mu \mathrm{M}$ to $\mathrm{AA}$ and TR standards.

On ORAC assay a solution of flouresceine $(1.4 \mathrm{nM})$ and other of AAPH $(4.8 \mathrm{mM})$ in phosphate buffer $(75 \mathrm{mM}, \mathrm{pH} 7.4)$ were prepared. $1.7 \mathrm{~mL}$ of AAPH, $1 \mathrm{~mL}$ of flouresceine and $300 \mu \mathrm{L}$ of diluted sample $(3000 \times)$ were mixed in the cell. Readings were made every $30 \mathrm{~min}$ at the wavelengths of excitation and emission of 485 and $523 \mathrm{~nm}$, respectively, until fluorescence became $0.5 \%$ of the initial value. The analytical signal for each sample was determined through the AUC by (Huang et al., 2002),

$\mathrm{AUC}=1+\frac{f_{1}}{f_{0}}+\frac{f_{2}}{f_{0}}+\cdots \frac{f_{n}}{f_{0}}$,

where $f_{0}$ is the initial fluorescence and $f_{n}$ is fluorescence in time $n$. The AC was determined by (Huang et al., 2002),

$\mathrm{AC}=\frac{\mathrm{AUC}_{\text {Sample }}-\mathrm{AUC}_{\text {Blank }}}{\mathrm{AUC}_{\text {Standard }}-\mathrm{AUC}_{\text {Blank }}} \times \frac{\text { Standard Concentration }}{\text { Sample Concentration }}$.

\subsection{Statistical analysis}

All AC values were analyzed by the Statistical Package for Social Science (SPSS, version 15.0). The one-way ANOVA test was used to identify the homogenous sub-groups between groups of samples. All observations were made independently. The application of this test is possible when the AC values obtained: (I) behave as a nor- mal distribution, and (II) with homogeneous variances between each group (homocedasticity). The confidence interval was 99\%. Normality was verified thought the Shapiro-Wilk test. In some cases, ACs were transformed to reach normality. Homocedasticity was tested by Levene test. The descriptive analysis of each variable includes several statistical parameters, such as average, variance, standard deviation, minimum and maximum value, graphic representation in box whiskers (Pestana \& Gageiro, 2005), and identification of outliers.

\section{Results and discussion}

The AOs in food and beverages that we ingest daily are of the most importance once the human being does not have the ability of eliminating some of the free radicals produced at a biological level. Since beers are produced from natural products, they have naturally occurring AOs that may constitute a barrier to radical damage. By testing AC of beers it is possible to estimate a relative degree of protection after AOs ingestion, but the results obtained vary with method and standard making their interpretation very difficult. In addition, since not all beers are equal, and in order to identify the ACs of beers and correlate these with their main components, it is essential to measure the effect of several factors of the chemical system. The identification of these factors is made by a qualitative characterization of the concerned samples.

\subsection{Qualitative characterization of samples}

From the chemical point of view, beers may contain naturally occurring compounds extracted from cereals, by-products of the fermentation process (typically ale or lager), and food additives. The former group may include colourants, flavours, AOs, sweeteners, alcohol, colour, acidity regulators, and juice, among other additives. The analyzed samples are distributed and/or composed as indicated in (Table 1); brand names were omitted and named $\mathrm{A}-\mathrm{H}$.

Each compound in beers behaving as an AO may contribute to enhance their AC. Regarding food additives, only AOs, flavours, juices and citric acid are expected to increase in a more or less extent the AC, due to their ability of avoiding the oxidation of coexisting compounds by means of their own oxidation.

\subsection{Determination of $A C$}

The AC of beers was tested by TRAP, TEAC, DPPH, FRAP, CUPRAC, and ORAC assays and evaluated against the standards AA, GA and TR (Table 2). In general, the results pointed out that all beers displayed AC properties, although the values varied a lot with the sample, method and standard. ACs were higher for ORAC assay despite the standard used. ORAC was the only method measuring fluorescence decay, which is technically much more sensitive to small variations in concentration. Thus, ORAC calibrations were established for much smaller concentration ranges of AOs, which corresponded to higher ACs in the samples.

In general, ACs were lower when GA was used as standard and higher when TR was used. These differences were a consequence of the different sensitivities and linear concentration ranges observed within calibrations obtained with different AO standards, which in turn resulted from the different kinetics observed for each AO. In this case, GA reacted lesser than other AOs. ACs for AA, GA and TR standards ranged from 30, 33, and 122-2,097, 14,672 and $29,106 \mu \mathrm{M}$, respectively. Samples number 8 and 2 displayed, in almost all methods and standards, the highest and the smallest ACs, respectively. In order to assess if these differences have statistical significance, ANOVA test was applied to these results. 
Table 1

Distribution by constitution parameter of the analyze samples.

\begin{tabular}{|c|c|c|c|c|c|c|c|c|c|c|c|c|}
\hline Brand & Name & $\begin{array}{l}\text { Fermentation } \\
\text { type }\end{array}$ & Origin & Colouring & Flavour & Antioxidant & Sweetner & Acidifier & $\begin{array}{l}\text { Alcohol } \\
(\%)\end{array}$ & Colour & Juice & $\begin{array}{l}\text { Other } \\
\text { additives }\end{array}$ \\
\hline \multirow[t]{9}{*}{ A } & 1 & Lager & Portuguese & $\begin{array}{l}\text { Caramel III } \\
\text { (E150) }\end{array}$ & With & Without & With & Without & 4 & Red & Without & With \\
\hline & 2 & Lager & Portuguese & Without & With & Without & With & Without & 4 & Gold & With & Without \\
\hline & 3 & Lager & Portuguese & Without & With & Without & With & $\begin{array}{l}\text { With (Citric } \\
\text { acid) }\end{array}$ & 0 & Gold & With & Without \\
\hline & 4 & Lager & Portuguese & Without & Without & Without & Without & Without & 0 & Gold & Without & Without \\
\hline & 5 & Lager & Portuguese & Without & With & Without & Without & Without & 0 & Gold & With & With \\
\hline & 6 & Lager & Portuguese & Without & Without & Without & Without & Without & 6 & Gold & Without & With \\
\hline & 7 & Ale & Portuguese & Without & Without & Without & Without & Without & 6 & Red & Without & Without \\
\hline & 8 & Ale & Portuguese & $\begin{array}{l}\text { Caramel III } \\
\text { (E150) }\end{array}$ & Without & Without & Without & Without & 5 & Black & Without & Without \\
\hline & 9 & Ale & Portuguese & $\begin{array}{l}\text { Caramel III } \\
\text { (E150) }\end{array}$ & With & Without & Without & Without & 0 & Black & Without & Without \\
\hline \multirow[t]{5}{*}{ B } & 10 & Lager & Portuguese & Without & Without & Without & Without & Without & 5 & Gold & Without & Without \\
\hline & 11 & Lager & Portuguese & Without & Without & Without & Without & Without & 4 & Gold & Without & Without \\
\hline & 12 & Lager & Portuguese & Without & Without & Without & Without & Without & 6 & Red & Without & Without \\
\hline & 13 & Lager & Portuguese & $\begin{array}{l}\text { Caramel III } \\
\text { (E150) }\end{array}$ & Without & Without & Without & Without & 7 & Black & Without & Without \\
\hline & 14 & Lager & Portuguese & $\begin{array}{l}\text { Caramel III } \\
\text { (E150) }\end{array}$ & Without & Without & Without & Without & 0 & Black & Without & Without \\
\hline \multirow[t]{5}{*}{ C } & 15 & Ale & Belgian & Without & Without & Without & Without & Without & 8 & Amber & Without & Without \\
\hline & 16 & Ale & Belgian & Without & Without & Without & Without & Without & 10 & $\begin{array}{l}\text { Reddish } \\
\text { brown }\end{array}$ & Without & Without \\
\hline & 17 & Ale & Belgian & Without & Without & $\begin{array}{l}\text { With (ascorbic } \\
\text { acid) }\end{array}$ & Without & Without & 9 & Amber & Without & Without \\
\hline & 18 & Ale & Belgian & Without & Without & $\begin{array}{l}\text { With (ascorbic } \\
\text { acid) }\end{array}$ & Without & Without & 7 & $\begin{array}{l}\text { Reddish } \\
\text { brown }\end{array}$ & Without & Without \\
\hline & 19 & Ale & Belgian & $\begin{array}{l}\text { Caramel III } \\
\text { (E150) }\end{array}$ & Without & $\begin{array}{l}\text { With (ascorbic } \\
\text { acid) }\end{array}$ & Without & Without & 7 & Amber & Without & With \\
\hline \multirow[t]{4}{*}{ D } & 20 & Ale & Belgian & Without & Without & Without & Without & Without & 7 & $\begin{array}{l}\text { Reddish } \\
\text { brown }\end{array}$ & Without & Without \\
\hline & 21 & Ale & Belgian & Without & Without & Without & Without & Without & 8 & $\begin{array}{l}\text { Reddish } \\
\text { brown }\end{array}$ & Without & Without \\
\hline & 22 & Ale & Belgian & Without & Without & Without & Without & Without & 7 & $\begin{array}{l}\text { Reddish } \\
\text { brown }\end{array}$ & Without & Without \\
\hline & 23 & Ale & Belgian & Without & Without & Without & Without & Without & 8 & Amber & Without & Without \\
\hline E & 24 & Lager & Portuguese & Without & Without & Without & Without & Without & 5 & Gold & Without & Without \\
\hline $\mathrm{F}$ & 25 & Lager & Portuguese & Without & Without & Without & Without & Without & 5 & Gold & Without & Without \\
\hline G & 26 & Lager & Portuguese & Without & Without & Without & Without & Without & 5 & Gold & Without & Without \\
\hline $\mathrm{H}$ & 27 & Lager & Portuguese & Without & Without & Without & Without & Without & 5 & Gold & Without & Without \\
\hline
\end{tabular}

Table 2a

AC mean $(\mu \mathrm{M})$ and standard deviation values for all methods and standards studied.

\begin{tabular}{|c|c|c|c|c|c|c|c|c|c|}
\hline \multirow[t]{2}{*}{ Sample } & \multicolumn{3}{|l|}{ TRAP } & \multicolumn{3}{|l|}{ TEAC } & \multicolumn{3}{|l|}{ DPPH } \\
\hline & $\mathrm{AA}$ & GA & TR & $\mathrm{AA}$ & GA & TR & $\mathrm{AA}$ & GA & TR \\
\hline 1 & $1489.5 \pm 24.8$ & $446.5 \pm 10.8$ & $1754.3 \pm 33.2$ & $734.3 \pm 45.8$ & $196.4 \pm 14.7$ & $736.2 \pm 57.0$ & $1048.9 \pm 28.9$ & $372.5 \pm 38.3$ & $1283.8 \pm 133.1$ \\
\hline 2 & $1126.2 \pm 78.9$ & $287.5 \pm 34.5$ & $1268.1 \pm 105.5$ & $606.4 \pm 0.0$ & $155.5 \pm 0.0$ & $577.1 \pm 0.0$ & $823.8 \pm 36.8$ & $419.7 \pm 62.5$ & $1447.8 \pm 217.1$ \\
\hline 3 & $1532.5 \pm 27.0$ & $465.3 \pm 11.8$ & $1811.8 \pm 36.2$ & $812.2 \pm 3.2$ & $221.3 \pm 1.0$ & $833.1 \pm 4.0$ & $1360.6 \pm 182.9$ & $573.0 \pm 48.4$ & $1980.1 \pm 168.0$ \\
\hline 4 & $1435.3 \pm 60.9$ & $422.8 \pm 26.6$ & $1681.8 \pm 81.4$ & $714.4 \pm 80.4$ & $190.1 \pm 25.7$ & $711.4 \pm 100.0$ & $1168.0 \pm 0.0$ & $326.2 \pm 0.6$ & $1123.0 \pm 2.0$ \\
\hline 5 & $1374.8 \pm 20.3$ & $396.3 \pm 8.9$ & $1600.7 \pm 27.1$ & $649.1 \pm 5.6$ & $169.2 \pm 1.8$ & $630.1 \pm 7.0$ & $1138.2 \pm 121.0$ & $597.1 \pm 373.4$ & $608.1 \pm 1296.6$ \\
\hline 6 & $1502.3 \pm 11.3$ & $452.1 \pm 4.9$ & $1771.3 \pm 15.1$ & $712.1 \pm 82.0$ & $189.3 \pm 26.2$ & $708.6 \pm 102.0$ & $876.8 \pm 9.2$ & $271.7 \pm 40.7$ & $934.0 \pm 141.3$ \\
\hline 7 & $1829.0 \pm 117.2$ & $595.1 \pm 51.3$ & $2208.4 \pm 156.8$ & $906.5 \pm 14.5$ & $251.5 \pm 4.6$ & $950.5 \pm 18.0$ & $1520.6 \pm 90.8$ & $437.5 \pm 60.8$ & $1509.7 \pm 211.0$ \\
\hline 8 & $1999.5 \pm 6.8$ & $669.7 \pm 3.0$ & $2436.6 \pm 9.0$ & $1098.6 \pm 30.5$ & $313.0 \pm 9.8$ & $1189.5 \pm 38.0$ & $2184.0 \pm 15.8$ & $594.2 \pm 9.4$ & $2053.9 \pm 32.8$ \\
\hline 9 & $1631.3 \pm 45.1$ & $508.6 \pm 19.7$ & $1944.0 \pm 60.3$ & $726.9 \pm 1.6$ & $194.1 \pm 0.5$ & $727.0 \pm 2.0$ & $1015.4 \pm 73.7$ & $292.4 \pm 50.1$ & $1005.7 \pm 174.1$ \\
\hline 10 & $1602.7 \pm 22.5$ & $496.0 \pm 9.9$ & $1905.7 \pm 30.2$ & $629.7 \pm 111.7$ & $163.0 \pm 35.7$ & $606.1 \pm 139.0$ & $1068.5 \pm 82.9$ & $301.1 \pm 30.1$ & $1036.1 \pm 104.5$ \\
\hline 11 & $1782.7 \pm 56.3$ & $574.8 \pm 24.7$ & $2146.6 \pm 75.4$ & $840.0 \pm 57.1$ & $230.2 \pm 18.3$ & $867.7 \pm 71.0$ & $1607.1 \pm 97.4$ & $477.2 \pm 8.3$ & $1647.7 \pm 28.7$ \\
\hline 12 & $1567.6 \pm 58.6$ & $480.7 \pm 25.6$ & $1858.7 \pm 78.4$ & $736.0 \pm 11.3$ & $197.0 \pm 3.6$ & $738.3 \pm 14.0$ & $1181.0 \pm 57.9$ & $329.0 \pm 83.8$ & $1132.8 \pm 290.9$ \\
\hline 13 & $1915.0 \pm 0.0$ & $632.7 \pm 0.0$ & $2323.6 \pm 0.0$ & $963.3 \pm 12.9$ & $269.7 \pm 4.1$ & $1021.2 \pm 16.0$ & $1627.6 \pm 100.0$ & $444.7 \pm 49.5$ & $1534.7 \pm 172.1$ \\
\hline 14 & $1766.8 \pm 11.3$ & $567.9 \pm 4.9$ & $2125.3 \pm 15.1$ & $799.1 \pm 15.3$ & $217.2 \pm 4.9$ & $816.8 \pm 19.0$ & $1274.1 \pm 13.2$ & $366.8 \pm 7.7$ & $1264.2 \pm 26.6$ \\
\hline 15 & $1836.9 \pm 2.3$ & $598.6 \pm 1.0$ & $2219.1 \pm 3.0$ & $813.3 \pm 46.6$ & $221.7 \pm 14.9$ & $834.5 \pm 58.0$ & $1494.9 \pm 23.3$ & $712.6 \pm 11.1$ & $1470.5 \pm 23.2$ \\
\hline 16 & $1970.8 \pm 15.8$ & $657.1 \pm 6.9$ & $2398.2 \pm 21.1$ & $883.2 \pm 37.8$ & $244.1 \pm 12.1$ & $921.5 \pm 47.0$ & $1580,4 \pm 6.7$ & $753.2 \pm 3.2$ & $1555.7 \pm 6.6$ \\
\hline 17 & $1722.2 \pm 56.3$ & $548.3 \pm 24.7$ & $2065.6 \pm 75.4$ & $827.5 \pm 36.2$ & $226.2 \pm 11.6$ & $852.2 \pm 45.0$ & $1442.3 \pm 95.4$ & $687.7 \pm 45.3$ & $1418.1 \pm 95.1$ \\
\hline 18 & $1930.9 \pm 22.5$ & $639.7 \pm 9.9$ & $2344.9 \pm 30.2$ & $936.1 \pm 40.2$ & $261.0 \pm 12.9$ & $987.3 \pm 50.0$ & $1511.3 \pm 86.6$ & $720.4 \pm 41.0$ & $1486.9 \pm 86.3$ \\
\hline 19 & $1554.8 \pm 9.0$ & $475.1 \pm 3.9$ & $1841.7 \pm 12.1$ & $659.3 \pm 13.7$ & $172.4 \pm 4.4$ & $642.8 \pm 17.0$ & $1145.7 \pm 71.0$ & $547.0 \pm 33.7$ & $1122.4 \pm 70.8$ \\
\hline 20 & $1835.3 \pm 54.1$ & $597.9 \pm 23.7$ & $2217.0 \pm 72.4$ & $894.0 \pm 17.7$ & $247.5 \pm 5.7$ & $934.9 \pm 22.0$ & $1392.1 \pm 182.0$ & $663.9 \pm 86.3$ & $1368.0 \pm 181.4$ \\
\hline 21 & $1997.9 \pm 18.0$ & $669.0 \pm 7.9$ & $2434.5 \pm 24.1$ & $1009.4 \pm 39.4$ & $284.4 \pm 12.6$ & $1078.5 \pm 49.0$ & $1679.3 \pm 13.3$ & $800.1 \pm 6.3$ & $1654.3 \pm 13.3$ \\
\hline 22 & $1727.0 \pm 247.9$ & $550.4 \pm 108.5$ & $2072.0 \pm 331.7$ & $982.1 \pm 47.4$ & $275.7 \pm 15.2$ & $1044.6 \pm 59.0$ & $1638.5 \pm 24.4$ & $780.7 \pm 11.6$ & $1613.6 \pm 24.3$ \\
\hline 23 & $1962.8 \pm 18.0$ & $653.6 \pm 7.9$ & $2387.6 \pm 24.1$ & $1009.9 \pm 9.6$ & $284.6 \pm 3.1$ & $1079.2 \pm 12.0$ & $1619.6 \pm 84.3$ & $771.8 \pm 40.0$ & $1594.8 \pm 84.1$ \\
\hline 24 & $1510.2 \pm 94.7$ & $455.6 \pm 41.4$ & $1782.0 \pm 126.7$ & $650.8 \pm 64.3$ & $169.7 \pm 20.6$ & $632.2 \pm 80.0$ & $920.5 \pm 76.6$ & $440.2 \pm 36.3$ & $898.0 \pm 76.3$ \\
\hline 25 & $1280.7 \pm 4.5$ & $355.1 \pm 2.0$ & $1474.9 \pm 6.0$ & $709.3 \pm 52.2$ & $188.4 \pm 16.7$ & $705.1 \pm 65.0$ & $747.1 \pm 37.7$ & $358.0 \pm 17.9$ & $725.1 \pm 37.6$ \\
\hline 26 & $1542.1 \pm 18.0$ & $469.5 \pm 7.9$ & $1824.6 \pm 24.1$ & $688.8 \pm 24.9$ & $181.9 \pm 8.0$ & $679.6 \pm 31.0$ & $753.3 \pm 139.8$ & $361.0 \pm 66.3$ & $731.4 \pm 139.4$ \\
\hline 27 & $1145.3 \pm 38.3$ & $295.9 \pm 16.8$ & $1293.7 \pm 51.3$ & $766.1 \pm 26.5$ & $206.6 \pm 8.5$ & $775.8 \pm 33.0$ & $1180.2 \pm 11.1$ & $563.4 \pm 5.3$ & $1156.8 \pm 11.1$ \\
\hline
\end{tabular}




\subsection{Effect of the method}

The effect of the method was tested individually for the three standards. The corresponding descriptive statistic data is presented in Table 3. The relative order of $A C$ per method was always DPPH $<$ TEAC $<$ FRAP $<$ CUPRAC $<$ TRAP $<$ ORAC for each standard.
Comparing all methods, then AC was about seven times higher for ORAC assays, as can be seen from the mean and standard errors plotted in Fig. 1. This observation may result from the different nature of the optical method used in this assay, the only one measuring emission of energy instead of absorbance. The box-plots in Fig. 1 confirm that ORAC is the assay with higher ACs in all stan-

Table 2b

AC mean $(\mu \mathrm{M})$ and standard deviation values for all methods and standards studied.

\begin{tabular}{|c|c|c|c|c|c|c|c|c|c|}
\hline \multirow[t]{2}{*}{ Sample } & \multicolumn{3}{|l|}{ FRAP } & \multicolumn{3}{|l|}{ CUPRAC } & \multicolumn{3}{|l|}{ ORAC } \\
\hline & AA & GA & TR & AA & GA & TR & AA & GA & TR \\
\hline 1 & $108.4 \pm 0.0$ & $272.6 \pm 0.0$ & $285.1 \pm 0.0$ & $1131.4 \pm 17.1$ & $278.0 \pm 4.7$ & $1387.5 \pm 21.3$ & $2985.3 \pm 225.7$ & $3131.5 \pm 136.3$ & $7585.5 \pm 254.1$ \\
\hline 2 & $31.9 \pm 0.0$ & $120.9 \pm 0.0$ & $181.5 \pm 0.0$ & $800.8 \pm 48.9$ & $186.8 \pm 13.5$ & $977.5 \pm 60.7$ & ND & $1046.4 \pm 764.1$ & $3697.3 \pm 1424.9$ \\
\hline 3 & $121.1 \pm 0.0$ & $297.8 \pm 0.0$ & $302.4 \pm 0.0$ & $1200.6 \pm 2.4$ & $297.1 \pm 0.7$ & $1473.4 \pm 3.0$ & $2477.2 \pm 821.3$ & $2824.7 \pm 495.9$ & $7013.3 \pm 924.8$ \\
\hline 4 & $155.1 \pm 0.0$ & $365.3 \pm 0.0$ & $348.4 \pm 0.0$ & $1005.0 \pm 39.2$ & $243.2 \pm 10.8$ & $1230.8 \pm 48.6$ & $2643.7 \pm 1566.4$ & $2925.2 \pm 945.9$ & $7200.9 \pm 1763.8$ \\
\hline 5 & $98.6 \pm 0.6$ & $253.2 \pm 1.2$ & $271.9 \pm 0.8$ & $1107.1 \pm 17.1$ & $271.4 \pm 4.7$ & $1357.5 \pm 21.3$ & $5753.1 \pm 1977.1$ & $4802.9 \pm 1193.9$ & $10702.2 \pm 2226.2$ \\
\hline 6 & $101.6 \pm 0.0$ & $259.1 \pm 0.0$ & $275.9 \pm 0.0$ & $1053.5 \pm 4.9$ & $256.6 \pm 1.4$ & $1290.9 \pm 6.1$ & $5408.2 \pm 672.7$ & $4594.6 \pm 406.2$ & $10313.8 \pm 757.4$ \\
\hline 7 & $179.3 \pm 0.6$ & $413.3 \pm 1.2$ & $381.3 \pm 0.8$ & $1666.1 \pm 19.6$ & $425.6 \pm 5.4$ & $2051.0 \pm 24.3$ & $13220.2 \pm 172.4$ & $9312.0 \pm 104.1$ & $19.110 .3 \pm 194.2$ \\
\hline 8 & $306.3 \pm 0.0$ & $665.3 \pm 0.0$ & $553.4 \pm 0.0$ & $2771.9 \pm 7.3$ & $730.7 \pm 2.0$ & $3423.0 \pm 9.1$ & $22096.7 \pm 3436.6$ & $14672.2 \pm 2075.2$ & $29105.6 \pm 3869.7$ \\
\hline 9 & $152.5 \pm 0.0$ & $360.2 \pm 0.0$ & $345.0 \pm 0.0$ & $1214.4 \pm 7.3$ & $301.0 \pm 2.0$ & $1490.6 \pm 9.1$ & $5705.4 \pm 2207.9$ & $4774.0 \pm 1333.2$ & $10648.4 \pm 2486.1$ \\
\hline 10 & $186.1 \pm 1.8$ & $426.8 \pm 3.6$ & $390.5 \pm 2.4$ & $918.5 \pm 9.8$ & $219.3 \pm 2.7$ & $1123.5 \pm 12.1$ & $2441.1 \pm 2609.4$ & $2802.9 \pm 1575.7$ & $6972.7 \pm 2938.2$ \\
\hline 11 & $188.2 \pm 86.5$ & $431.0 \pm 171.6$ & $393.4 \pm 117.3$ & $1489.6 \pm 48.9$ & $376.9 \pm 13.5$ & $1832.0 \pm 60.7$ & $5342.1 \pm 12.4$ & $4554.7 \pm 7.5$ & $10239.3 \pm 14.0$ \\
\hline 12 & $172.5 \pm 49.9$ & $399.8 \pm 98.9$ & $372.1 \pm 67.6$ & $1005.0 \pm 34.3$ & $243.2 \pm 9.5$ & $1230.8 \pm 42.5$ & $2995.6 \pm 2808.1$ & $3137.7 \pm 1695.7$ & $7597.1 \pm 3162.1$ \\
\hline 13 & $244.3 \pm 18.0$ & $542.2 \pm 35.8$ & $469.4 \pm 24.4$ & $1564.0 \pm 56.3$ & $397.4 \pm 15.5$ & $1924.3 \pm 69.8$ & $9384.7 \pm 410.5$ & $6995.8 \pm 247.9$ & $14791.4 \pm 462.2$ \\
\hline 14 & ND & $33.2 \pm 73.9$ & $121.6 \pm 50.5$ & $1340.8 \pm 166.4$ & $335.8 \pm 45.9$ & $1647.3 \pm 206.5$ & $4175.6 \pm 265.9$ & $3850.3 \pm 160.6$ & $8925.8 \pm 299.5$ \\
\hline 15 & $217.9 \pm 50.5$ & $490.0 \pm 100.1$ & $433.7 \pm 68.4$ & $1741.8 \pm 17.6$ & $439.7 \pm 4.9$ & $2141.7 \pm 21.9$ & $20773.8 \pm 1635.7$ & $13873.3 \pm 987.7$ & $27615.8 \pm 1841.8$ \\
\hline 16 & $191.6 \pm 22.8$ & $437.7 \pm 45.3$ & $398.0 \pm 30.9$ & $1800.0 \pm 111.6$ & $455.7 \pm 30.8$ & $2213.8 \pm 138.5$ & $16433.3 \pm 238.4$ & $11252.2 \pm 143.9$ & $22728.4 \pm 268.4$ \\
\hline 17 & $254.9 \pm 11.4$ & $563.3 \pm 22.6$ & $483.8 \pm 15.5$ & $1480.1 \pm 29.4$ & $367.5 \pm 8.1$ & $1817.1 \pm 36.4$ & $14249.8 \pm 894.7$ & $9933.7 \pm 540.2$ & $20269.6 \pm 1007.4$ \\
\hline 18 & $159.3 \pm 80.5$ & $373.7 \pm 159.7$ & $354.2 \pm 109.1$ & $1984.8 \pm 55.8$ & $506.7 \pm 15.4$ & $2443.1 \pm 69.2$ & $13620.3 \pm 5784.2$ & $9553.6 \pm 3492.8$ & $19560.9 \pm 6513.2$ \\
\hline 19 & $178.4 \pm 1.8$ & $411.6 \pm 3.6$ & $380.1 \pm 2.4$ & $1314.0 \pm 35.2$ & $321.6 \pm 9.7$ & $1611.0 \pm 43.7$ & $8839.9 \pm 706.6$ & $6666.8 \pm 426.7$ & $14177.9 \pm 795.7$ \\
\hline 20 & $162.7 \pm 13.2$ & $380.4 \pm 26.2$ & $358.8 \pm 17.9$ & $1446.9 \pm 182.1$ & $358.3 \pm 50.2$ & $1775.8 \pm 225.9$ & $15901.4 \pm 2501.3$ & $10931.0 \pm 1510.4$ & $22129.4 \pm 2816.6$ \\
\hline 21 & $240.9 \pm 2.4$ & $535.5 \pm 4.8$ & $464.8 \pm 3.3$ & $2157.1 \pm 129.2$ & $554.3 \pm 35.7$ & $2657.0 \pm 160.3$ & $18312.8 \pm 1595.2$ & $12387.2 \pm 963.3$ & $24844.8 \pm 1796.3$ \\
\hline 22 & $216.2 \pm 31.2$ & $486.6 \pm 62.0$ & $431.4 \pm 42.3$ & $2057.5 \pm 76.4$ & $526.8 \pm 21.1$ & $2533.3 \pm 94.7$ & $19056.3 \pm 2084.1$ & $12836.2 \pm 1258.5$ & $25681.9 \pm 2346.8$ \\
\hline 23 & $198.8 \pm 17.4$ & $452.1 \pm 34.6$ & $407.8 \pm 23.6$ & $2416.7 \pm 32.3$ & $625.9 \pm 8.9$ & $2979.1 \pm 40.1$ & $13961.7 \pm 1663.4$ & $9759.7 \pm 1004.5$ & $19945.3 \pm 1873.0$ \\
\hline 24 & $72.3 \pm 16.2$ & $200.9 \pm 32.2$ & $236.2 \pm 22.0$ & $922.5 \pm 36.7$ & $228.9 \pm 10.1$ & $1132.4 \pm 45.5$ & $209.9 \pm 1299.8$ & $1455.6 \pm 784.9$ & $4460.3 \pm 1463.7$ \\
\hline 25 & $30.2 \pm 15.6$ & $117.5 \pm 31.0$ & $179.2 \pm 21.2$ & $845.9 \pm 89.9$ & $207.8 \pm 24.8$ & $1037.4 \pm 111.6$ & $2052.2 \pm 3205.9$ & $2568.0 \pm 1935.9$ & $6534.8 \pm 3609.9$ \\
\hline 26 & $78.6 \pm 94.9$ & $213.6 \pm 188.3$ & $244.8 \pm 128.7$ & $857.6 \pm 47.7$ & $211.0 \pm 13.2$ & $1051.9 \pm 59.2$ & $1343.6 \pm 169.9$ & $2140.1 \pm 102.6$ & $5736.9 \pm 191.3$ \\
\hline 27 & $91.8 \pm 10.2$ & $239.7 \pm 20.3$ & $262.7 \pm 13.8$ & $1183.4 \pm 9.2$ & $300.9 \pm 2.5$ & $1456.1 \pm 11.4$ & $3690.5 \pm 1859.9$ & $3557.4 \pm 1123.1$ & $8379.6 \pm 2094.3$ \\
\hline
\end{tabular}

Table 3

Descriptive statistics of AC methods by method.

\begin{tabular}{|c|c|c|c|c|c|c|c|c|}
\hline \multirow[t]{2}{*}{ Method } & \multirow[t]{2}{*}{ Standard } & \multirow[t]{2}{*}{ Number of samples } & \multirow[t]{2}{*}{ Mean } & \multirow[t]{2}{*}{ Standard deviation } & \multicolumn{2}{|c|}{ Confidence interval 95\% } & \multirow[t]{2}{*}{ Minimum } & \multirow[t]{2}{*}{ Maximum } \\
\hline & & & & & Upper limit & Lower limit & & \\
\hline \multirow[t]{4}{*}{ TRAP } & AA & 27 & 1650.8 & 250.8 & 1551.6 & 1750.0 & 1126.2 & 1999.5 \\
\hline & AG & 27 & 517.1 & 109.7 & 473.7 & 560.5 & 287.5 & 669.7 \\
\hline & TR & 27 & 1970.1 & 335.5 & 1837.4 & 2102.8 & 1268.1 & 2436.6 \\
\hline & Total & 81 & 1379.3 & 674.2 & 1230.3 & 1528.4 & 287.5 & 2436.6 \\
\hline \multirow[t]{4}{*}{ TEAC } & $\mathrm{AA}$ & 27 & 805.9 & 133.9 & 752.9 & 858.8 & 606.4 & 1098.6 \\
\hline & AG & 27 & 219.3 & 42.8 & 202.4 & 236.3 & 155.5 & 313.0 \\
\hline & TR & 27 & 825.3 & 166.6 & 759.3 & 891.2 & 577.1 & 1189.5 \\
\hline & Total & 81 & 616.8 & 309.0 & 548.5 & 685.1 & 155.5 & 1189.5 \\
\hline \multirow[t]{4}{*}{ DPPH } & AA & 26 & 159.2 & 69.0 & 131.3 & 187.1 & 30.2 & 306.3 \\
\hline & AG & 27 & 360.9 & 149.4 & 301.8 & 420.0 & 33.2 & 665.3 \\
\hline & $\mathrm{TR}$ & 27 & 345.5 & 102.1 & 305.1 & 385.8 & 121.6 & 553.4 \\
\hline & Total & 80 & 290.1 & 143.8 & 258.1 & 322.1 & 30.2 & 665.3 \\
\hline \multirow[t]{4}{*}{ FRAP } & $\mathrm{AA}$ & 27 & 1296.3 & 341.6 & 1161.1 & 1431.4 & 747.1 & 2184.0 \\
\hline & AG & 27 & 517.2 & 172.1 & 449.1 & 585.2 & 271.7 & 800.1 \\
\hline & TR & 27 & 1363.4 & 362.9 & 1219.9 & 1507.0 & 725.1 & 2063.7 \\
\hline & Total & 81 & 1059.0 & 489.6 & 950.7 & 1167.2 & 271.7 & 2184.0 \\
\hline \multirow[t]{4}{*}{ CUPRAC } & $\mathrm{AA}$ & 27 & 1425.1 & 510.6 & 1223.1 & 1627.1 & 800.8 & 2771.9 \\
\hline & AG & 27 & 358.1 & 137.9 & 303.5 & 412.6 & 186.8 & 730.7 \\
\hline & TR & 27 & 1751.5 & 632.1 & 1501.4 & 2001.5 & 977.5 & 3423.0 \\
\hline & Total & 81 & 1178.2 & 761.1 & 1009.9 & 1346.5 & 186.8 & 3423.0 \\
\hline \multirow[t]{4}{*}{ ORAC } & $\mathrm{AA}$ & 26 & 8964.4 & 6852.3 & 6196.7 & 11732.1 & 209.9 & 22096.7 \\
\hline & AG & 27 & 6531.1 & 4203.0 & 4868.5 & 8193.7 & 1046.4 & 14672.2 \\
\hline & TR & 27 & 13924.8 & 7837.3 & 10824.4 & 17025.1 & 3697.3 & 29105.6 \\
\hline & Total & 80 & 9817.3 & 7112.3 & 8234.5 & 11400.1 & 209.9 & 29105.6 \\
\hline
\end{tabular}


dards, showing significant statistical differences to the other studied methods. Their corresponding ACs ranged from 210 to $29,106 \mu \mathrm{M}$.

The method displaying the lower ACs in all standards was always DPPH. The mean values of CUPRAC and TRAP methods are very similar, lying within 272-2064 and 187-3423, respectively.

The ANOVA test was carried out for the hypothesis: (i) $H_{0}$ : $\mu_{\mathrm{FRAP}}=\mu_{\mathrm{TEAC}}=\mu_{\mathrm{TRAP}}=\mu_{\mathrm{DPPH}}=\mu_{\mathrm{CUPRAC}}=\mu_{\mathrm{ORAC}}$ and (ii) $H_{1}: \mu_{\mathrm{FRAP}} \neq$ $\mu_{\mathrm{TEAC}} \neq \mu_{\mathrm{TRAP}} \neq \mu_{\mathrm{DPPH}} \neq \mu_{\mathrm{CUPRAC}} \neq \mu_{\mathrm{ORAC}}$. The $F$ test gave $p<0.01$, thus rejecting the null hypothesis $\left(H_{0}\right)$. Post-hoc test showed only two homogeneous sub-groups: one with DPPH, TEAC, FRAP, CUPRAC, and TRAP, and the other with ORAC. This confirmed the statistical difference between ORAC and the other AC assays.

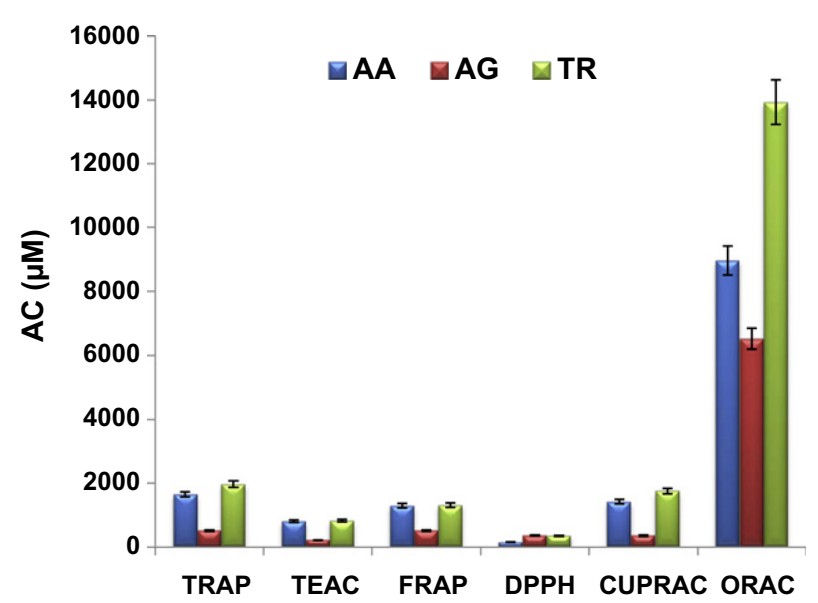

Fig. 1. Antioxidant capacity for the various assays and standards.

\subsection{Effect of standard}

The antioxidant "power" of each AO varies with its chemical nature, for which the mean ACs for each standard were also found different, as may be seen in Table 1 and Fig. 2. All assays showed lower AC when GA was used as standard, with the exception of the DPPH assay in which the lower AC value was obtained for AA. For all the studied assays (once again with the exception of the DPPH assay) the higher ACs were obtained having TR as standard. For the DPPH assay the higher value of AC was obtained for the AG standard (Table 4).

The statistical significance of these differences was evaluated by ANOVA test, considering separately the results of each method. The hypotheses were: (i) $H_{0}: \mu_{\mathrm{AA}}=\mu_{\mathrm{AG}}=\mu_{\mathrm{TR}}$ and (ii) $H_{1}: \mu_{\mathrm{AA}} \neq \mu_{\mathrm{AG}}$ $\neq \mu_{\mathrm{TR}}$. The $F$ test gave $p<0.01$, thus rejecting the null hypothesis $\left(H_{0}\right)$.

Post-hoc tests showed at least one standard different than the others for all methods. For TEAC, FRAP, and DPPH methods, GA showed significant statistical differences from AA and TR.

For ORAC method, TR was different from the other standards and for TRAP and CUPRAC methods all standards were different. Therefore, there are significant statistical differences between standards, but the observed pattern depends on the way the AC is assessed.

\subsection{Effect of the sample}

ANOVA was used to evaluate the effect of each parameter described in sample characterization. Normality and homocedasticity of the observations were assured in every test. This study was made separately for each factor and grouping results according to the assay used. The factors commercial brand, fermentation, origin, alcohol and colour presented no statistical differences displaying always homogenous sub-groups.
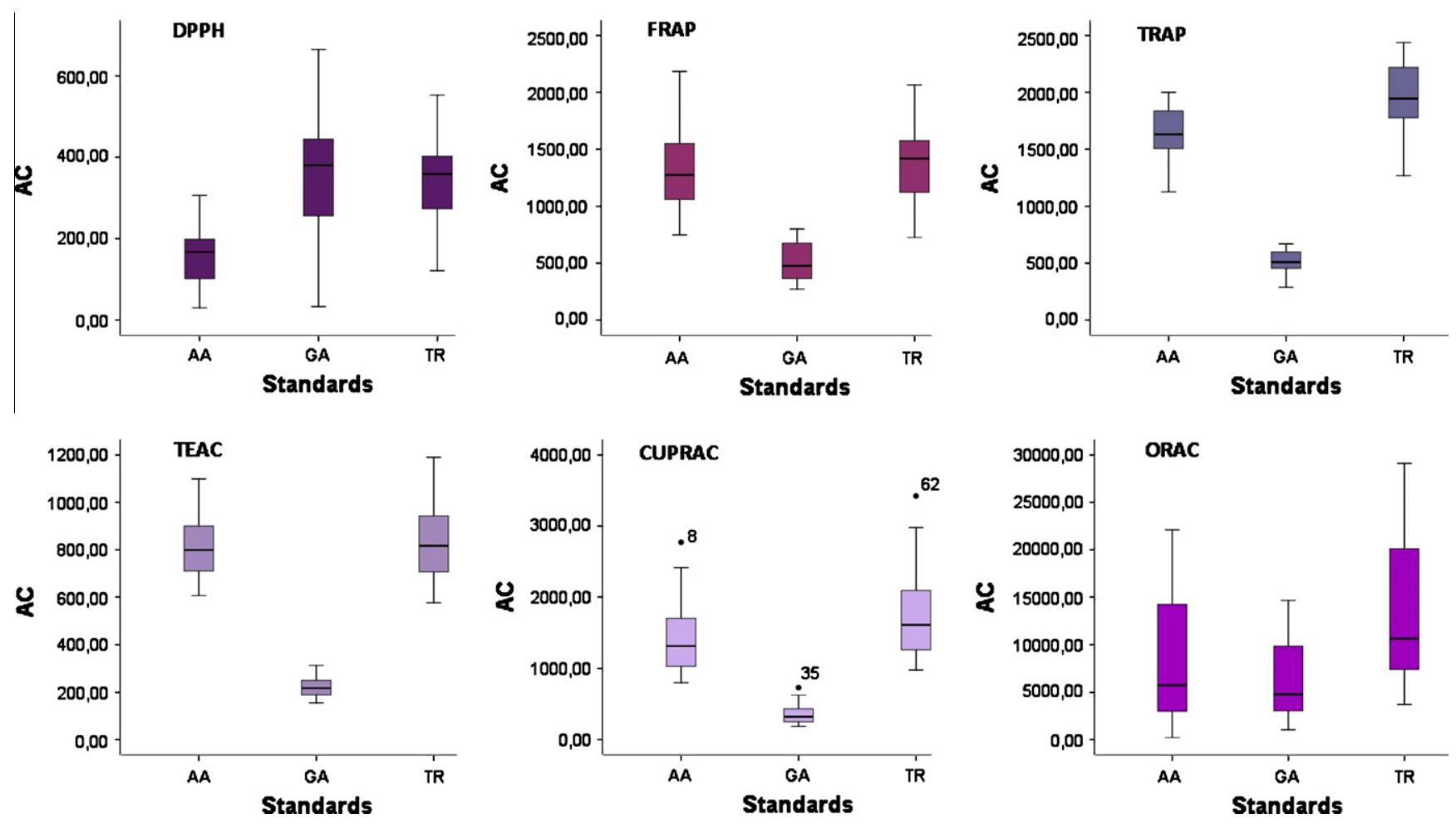

Fig. 2. Effect of the standard statistical analysis according the method used. 
Table 4

Descriptive statistics of AC methods by standard.

\begin{tabular}{|c|c|c|c|c|c|c|c|c|}
\hline \multirow[t]{2}{*}{ Method } & \multirow[t]{2}{*}{ Standard } & \multirow[t]{2}{*}{ Number of samples } & \multirow[t]{2}{*}{ Mean } & \multirow[t]{2}{*}{ Standard deviation } & \multicolumn{2}{|c|}{ Confidence interval 95\% } & \multirow[t]{2}{*}{ Minimum } & \multirow[t]{2}{*}{ Maximum } \\
\hline & & & & & Upper limit & Lower limit & & \\
\hline \multirow[t]{7}{*}{ AA } & TRAP & 27 & 1650.8 & 250.8 & 1551.6 & 1750.0 & 1126.2 & 1999.5 \\
\hline & TEAC & 27 & 805.9 & 133.9 & 752.9 & 858.8 & 606.4 & 1098.6 \\
\hline & $\mathrm{DPPH}$ & 26 & 159.2 & 69.0 & 131.3 & 187.1 & 30.2 & 306.3 \\
\hline & FRAP & 27 & 1296.3 & 341.6 & 1161.1 & 1431.4 & 747.1 & 2184.0 \\
\hline & CUPRAC & 27 & 1425.1 & 510.6 & 1223.1 & 1627.1 & 800.8 & 2771.9 \\
\hline & ORAC & 26 & 8964.4 & 6852.3 & 6196.7 & 11732.1 & 209.9 & 22096.7 \\
\hline & Total & 160 & 2356.4 & 4027.3 & 1727.6 & 2985.2 & 30.2 & 22096.7 \\
\hline \multirow[t]{7}{*}{ GA } & TRAP & 27 & 517.1 & 109.7 & 473.7 & 560.5 & 287.5 & 669.7 \\
\hline & TEAC & 27 & 219.3 & 42.8 & 202.4 & 236.3 & 155.5 & 313.0 \\
\hline & DPPH & 27 & 360.9 & 149.4 & 301.8 & 420.0 & 33.2 & 665.3 \\
\hline & FRAP & 27 & 517.2 & 172.1 & 449.1 & 585.2 & 271.7 & 800.1 \\
\hline & CUPRAC & 27 & 358.1 & 137.9 & 303.5 & 412.6 & 186.8 & 730.7 \\
\hline & ORAC & 27 & 6531.1 & 4203.0 & 4868.5 & 8193.7 & 1046.4 & 14672.2 \\
\hline & Total & 162 & 1417.3 & 2853.0 & 974.6 & 1859.9 & 33.2 & 14672.2 \\
\hline \multirow[t]{7}{*}{ TR } & TRAP & 27 & 1970.1 & 335.5 & 1837.4 & 2102.8 & 1268.1 & 2436.6 \\
\hline & TEAC & 27 & 825.3 & 166.6 & 759.3 & 891.2 & 577.1 & 1189.5 \\
\hline & DPPH & 27 & 345.5 & 102.1 & 305.1 & 385.8 & 121.6 & 553.4 \\
\hline & FRAP & 27 & 1363.4 & 362.9 & 1219.9 & 1507.0 & 725.1 & 2063.7 \\
\hline & CUPRAC & 27 & 1751.5 & 632.1 & 1501.4 & 2001.5 & 977.5 & 3423.0 \\
\hline & ORAC & 27 & 13924.8 & 7837.3 & 10824.4 & 17025.1 & 3697.3 & 29105.6 \\
\hline & Total & 162 & 3363.4 & 5725.0 & 2475.2 & 4251.7 & 121.6 & 29105.6 \\
\hline
\end{tabular}

Commercial brand D showed the highest AC values, followed by C. While brands A and B displayed very similar ACs for TRAP, TEAC, DPPH and FRAP methods, the brand A had higher ACs then B for CUPRAC method and lower for ORAC method. Samples E, F, G and $\mathrm{H}$ had the lowest values of AC.

Ale beers had a slightly higher AC than lager samples for all methods and standards studied. Portuguese beers showed a slightly lower AC than Belgian samples, regardless of the method or standard.

The samples with flavourings had a higher AC than those without this component for all methods, except ORAC that gave the opposite result. The samples with and without colouring had very similar values for all methods and standards.

The samples with sweeteners, juice and other additives have higher ACs then those samples that did not have these compounds, although there were no significant statistical differences between the observed groups.

The reddish brown samples had higher ACs than the other colours. This was followed by the beers of ambar, red, black and gold colours. Beers with $7 \%$ and $8 \%$ of alcohol had higher AC then de samples of $0 \%, 4 \%, 5 \%$ and $6 \%$.

Globally, most methods suggested statistical differences between beers of different colours. The commercial brand, origin of samples, fermentation, and alcohol content did not seem determinant factors because only some or few methods showed significant statistical differences between the observed samples. Flavouring, $\mathrm{AO}$, sweeteners, juice and other additives were not statistically relevant for the observed AC differences.

\section{Conclusions}

The beers were from different brands, fermentation (ale or lager), origins (Portuguese and Belgium), food colouring, flavours, sweeteners, antioxidants, juice content, acidity regulator, alcohol content and colour. Their ACs were assayed by TRAP, TEAC, DPPH, FRAP, CUPRAC and ORAC, against three different standards (AA, GA, TR).

The highest AC values were obtained using ORAC and the lowest values were obtained by DPPH. TR was the standard, regardless of the assay, that achieved highest ACs. GA was on the other hand, for all assays except for DPPH, the standard that obtained the lowest AC. The different commercial brands tested showed statistical differences between themselves only on FRAP method. Lager type beers had lower AC than the ale ones, and Portuguese beers showed slightly lower ACs then Belgian ones. The reddish-brown beers displayed a higher AC followed by the amber, red, black and gold beers. Results showed that higher alcohol content provides higher $\mathrm{AC}$ values. The samples with food colouring had a higher AC then the ones without it, for every method except the ORAC, in this method the results were reverse. Beers with sweeteners, flavours, antioxidants and other additives had a slightly higher AC than the samples without it.

Statistical analysis pointed out that some intrinsic aspects of the samples and the experimental procedure could provide some statistical differences in ACs. The method and the colour of the sample (on most methods) affected significantly the AC.

\section{References}

Apak, R., Güçlü, K., Demirata, B., Özyürek, M., Çelik, S. E., Bektaşoğlu, B., et al. (2007). Comparative evaluation of various total antioxidant capacity assays applied to phenolic compounds with the CUPRAC assay. Molecules, 12(7), 1496-1547.

Benzie, I. F. F., \& Strain, J. J. (1996). The ferric reducing ability of plasma (FRAP) as a measure of "Antioxidant Power": The FRAP assay. Analytical Biochemistry, 239(1), 70-76.

Benzie, I. F. F., \& Strain, J. J. (1999). Ferric reducing/antioxidant power assay: Direct measure of total antioxidant activity of biological fluids and modified version for simultaneous measurement of total antioxidant power and ascorbic acid concentration. Methods in Ezymology, 299, 15-27.

Campos, A., Escobar, J., \& Lissi, E. A. (1996). The total reactive antioxidant potential (TRAP) and total antioxidant reactive (TAR) of ilex paraguayensis extracts and red wine. Journal of the Brazilian Chemical Society, 7(1), 43-49.

Ghiselli, A., Natella, F., Guidi, A., Montanari, L., Fantozzi, P., \& Scaccini, C. (2000b). Beer increases plasma antioxidant capacity in humans. Journal of Nutritional Biochemistry, 11(2), 76-80.

Ghiselli, A., Serafini, M., Natella, F., \& Scaccini, C. (2000a). Total antioxidant capacity as a tool to assess redox status: Critical view and experimental data. Free Radical Biology and Medicine, 29(11), 1106-1114.

Girotti, S., Bolelli, L., Fini, F., Budini, R., \& Arfelli, G. (2002). Chemiluminescent determination of antioxidant capacity of beverages. Italian Journal of Food Science, 14(2), 113-122.

Halliwell, B. (2007). Biochemistry of oxidative stress. Biochemical Society Transactions, 35(5), 1147-1149.

Huang, D., Ou, B., Hampsch-Woodill, M., Flanagan, J. A., \& Prior, R. L. (2002). Highthroughput assay of oxygen radical absorbance capacity (ORAC) using a multichannel liquid handling system coupled with a microplate fluorescence reader in 96-well format. Journal of Agricultural and Food Chemistry, 50(16), 4437-4444. 
Huang, D., Ou, B., \& Prior, R. L. (2005). The chemistry behind antioxidant capacity assays. Journal of Agriculture and Food Chemistry, 53(6), 1841-1856.

Kurechi, T., Kikugawa, K., \& Kato, T. (1980). Studies on the Antioxidants. XIII. Hydrogen donating capability of antioxidants to 2,2-diphenyl-1-picrylhydrazyl. Chemical \& Pharmaceutical Bulletin, 28(7), 2089-2093.

Mello, L. D., \& Kubota, L. T. (2007). Biosensors as a tool for the antioxidant status evaluation. Talanta, 72(2), 335-348.

Miller, N. J., Rice-Evans, C., Davies, M. J., Gopinathan, V., \& Milner, A. (1993). A novel method for measuring antioxidant capacity and its application to monitoring the antioxidant status in premature neonates. Clinical Science, 84, 407-412.

Obón, J. M., Castellar, M. R., Cascales, J. A., \& Fernández-López, J. A. (2005). Assessment of the TEAC method for determining the antioxidant capacity of synthetic red food colorants. Food Research International, 38(8-9), 843-845.

Ou, B., Huang, D., Hampsch-Woodill, M., Flanagan, J. A., \& Deemer, E. K. (2002) Analysis of antioxidant activities of common vegetables employing oxygen radical absorbance capacity (ORAC) and ferric reducing antioxidant power (FRAP) assays: A comparative study. Journal of Agricultural and Food Chemistry, 50(11), 3122-3128.

Pérez-Jiménez, J., Arranz, S, Tabernero, M., Díaz-Rubio, M. E Serrano, J., Goñi, I. et al. (2008). Updated methodology to determine antioxidant capacity in plant foods, oils and beverages: Extraction, measurement and expression of results. Food Research International, 41(3), 274-285.

Pestana, M. H., \& Gageiro, J. (2005). Análise de dados para ciências sociais, a complementariedade do SPSS (4th ed.). Portugal: Edições Sílabo.
Prior, R. L., Wu, X., \& Schaich, K. (2005). Standardized methods for the determination of antioxidant capacity and phenolics in foods and dietary supplements. Journal of Agricultural and Food Chemistry, 53(10), 4290-4302.

Pulido, R., Bravo, L., \& Saura-Calixto, F. (2000). Antioxidant activity of dietary polyphenols as determined by a modified ferric reducing/antioxidant power assay. Journal of Agricultural and Food Chemistry, 48(8), 3396-3402.

Re, R., Pellegrini, N., Proteggente, A., Pannala, A., Yang, M., \& Rice-Evans, C. (1999). Antioxidant activity applying an improved ABTS radical cation decolorization assay. Free Radical Biology and Medicine, 26(9-10), 1231-1237.

Serrano, J., Goñi, I., \& Saura-Calixto, F. (2007). Food antioxidant capacity determined by chemical methods may underestimate the physiological antioxidant capacity. Food Research International, 40(1), 15-21.

Vasconcelos, S. M. L., Goulart, M. O. F., Moura, J. B. D. F., Manfredini, V., Benfato, M. S., \& Kubota, L. T. (2007). Reactive oxygen and nitrogen species, antioxidants and markers of oxidative damage in human blood: Main analytical methods for their determination. Química Nova, 30(5), 1323-1338.

Wayner, D., Burton, G., Ingold, K., \& Locke, S. (1985). Quantitative measurement of the total, peroxyl radical-trapping antioxidant capability of human blood plasma by controlled peroxidation: The important contribution made by plasma proteins. FEBS Letters, 187(1), 33-37.

Wei, A., Mura, K., \& Shibamoto, T. (2001). Antioxidative activity of volatile chemicals extracted from beer. Journal of Agricultural and Food Chemistry, 49(8), 4097-4101. 